Pacific Journal of Mathematics

ASYMPTOTICS FOR A CLASS OF WEIGHTED EIGENVALUE 


\title{
ASYMPTOTICS FOR A CLASS OF WEIGHTED EIGENVALUE PROBLEMS
}

\author{
PHILIP W. WALKER
}

\begin{abstract}
This paper deals with the asymptotic behavior at infinity of the solutions to $\zeta(y)=\lambda w y$ on $[a, \infty)$ where $\ell$ is an $n$th order ordinary linear differential operator, $\lambda$ is a nonzero complex number and $w$ is a suitably chosen positive valued continuous functions. As an application the deficiency indices of certain symmetric differential operators in Hilbert space are computed.
\end{abstract}

1. Preliminaries. Throughout the first three sections $\ell$ will denote an operator of the form,

$$
\ell(y)=y^{(n)}+\sum_{k=2}^{n} p_{k} y^{(n-k)} \text { on }[a, \infty),
$$

where each of $p_{2}, \cdots, p_{n}$ is a continuous complex valued function on $[a, \infty)$. In view of the transformation indicated on p. 309 of [2] it results in no great loss of generality to take the coefficient of $y^{(n-1)}$ to be zero, and in order to simplify the exposition we shall do this. We shall be concerned with the behavior at infinity of the solutions to

$$
\ell(y)=\lambda w y \text { on }[a, \infty)
$$

where $\lambda$ is a nonzero complex number and $w$ is an appropriate weight (i.e., positive valued continuous function). For a given $\ell$ we shall consider the weights $w$ indicated by the following definition. $\mathscr{L}(a, \infty)$ denotes the Banach space of all complex valued measurable functions which are absolutely Lebesgue integrable on $[a, \infty)$.

Definition. If $\ell$ is as in 1.1 the statement that $w$ is an $\ell$-admissible weight means that

(1) $w$ is differentiable, strictly increasing, and unbounded on $[a, \infty)$;

(2) each of $\left[w^{\prime} / w^{1+1 / n}\right]^{\prime}$ and $\left[\left(w^{\prime} / w\right)^{2}\left(1 / w^{1 / n}\right)\right]$ is continuous on $[a, \infty)$ and is in $\mathscr{L}(a, \infty)$; and

(3) $p_{j} / w^{(j-1) / n} \in \mathscr{L}(a, \infty)$ for $j=2,3, \cdots, n$.

For example if $\ell(y)(t)=y^{\prime \prime}(t) \pm t^{\alpha} y(t)$ for $t \geqq 1$ and $w(t)=t^{\beta}$ then $w$ will be an $\ell$-admissible weight if and only if $\beta>0$ and $\beta>$ $2(\alpha+1)$.

We shall demonstrate that when $w$ is an $\ell$-admissible weight the solutions of 1.2 have a particularly simple asymptotic behavior and 
we shall establish that every operator of the form 1.1 has admissible weights.

Our asymptotic theorem relies on the classic perturbation theorem of Norman Levinson [2, Therem 8.1 p. 92 or 10]. Recent related works include $[3,7,8,9,11$, and 12]. The results in $\S 4$ complement those of reference [13].

2. Results. Our main results are stated in the following two theorems.

THEOREM 1. If $\ell$ is as in 1.1 and $U$ is a continuous function on $[a, \infty)$ there is an $\ell$-admissible weight $w$ with $w(t) \geqq U(t)$ for $t \geqq a$.

THEOREM 2. If $\ell$ is as in 1.1, $w$ is an $\ell$-admissible weight, and $\lambda$ is a nonzero complex number then equation 1.2 has $n$ linearly independent solutions $y_{1}, \cdots, y_{n}$ such that for $k=0, \cdots, n-1$

$$
y_{j}^{(k)}(t) w^{\alpha_{k}}(t) e^{-\mu_{j} h(t)} \longrightarrow \mu_{j}^{k} \text { as } t \longrightarrow \infty,
$$

where

$$
h(t)=\int_{a}^{t} w^{1 / n},
$$

$\mu_{1}, \cdots, \mu_{n}$ are the distinct $n$th roots of $\lambda$, and $\alpha_{k-1}=(n-2 k+1) / 2 n$ for $k=1, \cdots, n$.

3. Proofs. The proof of Theorem 1 will be facilitated by the following results.

Lemma. If $r>1$ and $1<c<d$ there exist positive constants $M_{r}$ and $N_{r}$, depending only on $r$, and a function $f$ defined on $[0,1]$ such that

(1) $f$ is continuously differentiable, strictly increasing, $f(0)=c$, $f(1)=d$, and $f^{\prime}(0)=0=f^{\prime}(1)$;

(2) $\left[f^{\prime} / f^{r}\right]^{\prime}$ exists and is continuous on $[0,1]$ and has the value 0 at 0 and at 1 ; and

(3) $\left|\left[f^{\prime} \mid f^{r}\right]^{\prime}(x)\right| \leqq M_{r} c^{1-r} \quad$ and $\quad\left[\left(f^{\prime} \mid f\right)^{2} f^{1-r}\right](x) \leqq N_{r} c^{1-r} \quad$ for all $x \in[0,1]$.

Proof. Given $r>1$ and $1<c<d$ let $g:[0,1] \rightarrow[0,1]$ be a twice continuously differentiable fuction such that $g(0)=0, g(1)=1, g^{\prime}(x)>0$ for $x \in(0,1)$, and $g^{\prime}(0)=g^{\prime \prime}(0)=g^{\prime}(1)=g^{\prime \prime}(1)=0$ (e.g. let $g(x)=h(h(x))$ where $\left.h(x)=\left(2 x-x^{2}\right)^{2}\right)$. Then let $f:[0,1] \rightarrow[c, d]$ be given by

$$
f=\left\{c^{1-r}-6\left(c^{1-r}-d^{1-r}\right)\left[\left(\frac{1}{2}\right) g^{2}-\left(\frac{1}{3}\right) g^{3}\right]\right\}^{1 /(1-r)},
$$


clearly $f(0)=c$ and $f(1)=d$. Since each of $g$ and the function whose value at $x$ is $(1 / 2) x^{2}-(1 / 3) x^{3}$ is strictly increasing on $[0,1]$ and since $1-r<0$ and $1<c<d$ we see that $f$ is strictly increasing on $[0,1]$. Using the above listed properties of $g$ we see that $f^{\prime}$ is continuous on $[0,1]$ and that $f^{\prime}(0)=0=f^{\prime}(1)$. Computation shows that

$$
\left[f^{\prime} / f^{r}\right]=(6 /(r-1))\left(c^{1-r}-d^{1-r}\right)\left(g-g^{2}\right) g^{\prime}
$$

and

$$
\left[f^{\prime} / f^{r}\right]^{\prime}=(6 /(r-1))\left(c^{1-r}-d^{1-r}\right)\left[(1-2 g)\left(g^{\prime}\right)^{2}+\left(g-g^{2}\right) g^{\prime \prime}\right] .
$$

Hence condition (2) of the lemma is satisfied. Letting $M_{r}$ be a bound for $(6 /(r-1))\left[(1-2 g)\left(g^{\prime}\right)^{2}+\left(g-g^{2}\right) g^{\prime \prime}\right]$ on $[0,1]$ we see that

$$
\left|\left[f^{\prime} / f^{r}\right]^{\prime}(x)\right| \leqq M_{r} c^{1-r} \text { for } x \in[0,1] \text {. }
$$

Noting that $c^{1-r} \geqq(f(x))^{1-r} \geqq d^{1-r}$ for $x \in[0,1]$ and letting $N_{r}$ be a bound for $\left[(6 /(r-1))\left(g-g^{2}\right) g^{\prime}\right]^{2}$ on $[0,1]$ we see that

$$
\left|\left[\left(f^{\prime} / f^{r}\right)^{2} f^{1-r}\right](x)\right| \leqq N_{r} c^{3(1-r)} \leqq N_{r} c^{1-r}
$$

for $x \in[0,1]$, and the lemma is proved.

Proof of Theorem 1. We shall make use of the fact that if $U$ is a continuous function on $[a, \infty)$ and $\gamma$ is a positive number there is a weight $w$ such that $U / w^{\prime} \in \mathscr{P}(a, \infty)$. To see this let $w$ be such that

$$
\frac{1+|U(t)|}{w^{r}(t)}=\frac{1}{(t-a+1)^{2}}
$$

Given an $\ell$ as in 1.1 and a continuous function $U$ on $[a, \infty)$ choose weights $v_{2}, v_{3}, \cdots, v_{n}$ such that $p_{j} / v_{j}^{(j-1) / n} \in \mathscr{P}(\alpha, \infty)$ for $j=$ $2, \cdots, n$ and let $v$ be a weight such that $v(t) \geqq \max \left\{U(t), v_{2}(t), \cdots, v_{n}(t)\right\}$ for all $t \geqq a$. Next let $\left\{c_{k}\right\}_{k=1}^{\infty}$ be a strictly increasing sequence of numbers with $c_{k} \geqq k^{2 n}$ and $c_{k} \geqq$ maximum of $v(t)$ for $t \in[a+k-1, a+k]$ and let $f_{k}$ be a function satisfying the conclusion to the lemma with $r=1+1 / n, c=c_{k}$ and $d=c_{k+\imath}$ for each $k$. Let $w$ be defined by

$$
w(t)=f_{k}(t-a-k+1) \text { for } t \in[a+k-1, \alpha+k] \text {. }
$$

Clearly then $w$ satisfies condition (1) in the definition of admissible weight, and since $w(t) \geqq v(t)$, we see that $w(t) \geqq U(t)$ and $w$ satisfies condition (3) of the definition. To see that condition (2) is satisfied note that 


$$
\begin{aligned}
\int_{a}^{\infty}\left|\left[w^{\prime} \mid w^{1+1 / n}\right]^{\prime}\right| & =\sum_{k=1}^{\infty} \int_{0}^{1}\left|\left[f_{k}^{\prime} / f_{k}^{1+1 / n}\right]^{\prime}\right| \\
& \leqq \sum_{k=1}^{\infty} M_{1+1 / n} c_{k}^{-1 / n} \leqq M_{1+1 / n} \sum_{k=1}^{\infty} k^{-2}<\infty,
\end{aligned}
$$

and

$$
\begin{aligned}
\left.\int_{a}^{\infty}\left[w^{\prime} / w\right)^{2}\left(1 / w^{1 / n}\right)\right] & =\sum_{k=1}^{\infty} \int_{0}^{1}\left[\left(f_{k}^{\prime} / f_{k}\right)^{2} f_{k}^{-1 / n}\right] \\
& \leqq \sum_{k=1}^{\infty} N_{1+1 / n} c_{k}^{-1 / n} \leqq N_{1+1 / n} \sum_{k=1}^{\infty} k^{-2}<\infty
\end{aligned}
$$

Proof of Theorem 2. We shall establish the theorem by showing that the standard vector-matrix formulation,

$$
y^{\prime}=\left[\begin{array}{cccccr}
0 & 1 & 0 & \cdots & 0 & 0 \\
0 & 0 & 1 & \cdots & 0 & 0 \\
\cdots & \ldots & \cdots & \cdots & \ldots & \ldots \\
0 & 0 & 0 & \cdots & 0 & 1 \\
\left(\lambda w-p_{n}\right) & -p_{n-1} & -p_{n-2} & \cdots & -p_{2} & 0
\end{array}\right] y
$$

of equation (1.2) has a fundamental matrix $Y_{0}$ such that

$$
Q(t) Y_{0}(t) E(t) \longrightarrow L \text { as } t \longrightarrow \infty,
$$

where

$$
Q=\operatorname{diag}\left[w^{\alpha_{1}}, \cdots, w^{\alpha} n\right]
$$

with $\alpha_{k}=(n-2 k+1) / 2 n$ for $k=1, \cdots, n$;

$$
E(t)=\operatorname{diag}\left[e^{-\mu_{1} h(t)}, \cdots, e^{-\mu_{n} h(t)}\right]
$$

with $\mu_{1}, \cdots, \mu_{n}$ the distinct $n$th roots of $\lambda$ and

$$
h(t)=\int_{a}^{t} w^{1 / n}
$$

and

$$
L=\left[\begin{array}{llll}
1 & 1 & \cdots & 1 \\
\mu_{1} & \mu_{2} \cdots & \mu_{n} \\
\mu_{1}^{2} & \mu_{2}^{2} \cdots & \mu_{n}^{2} \\
\cdots \cdots \cdots & \cdots \cdots \\
\mu_{1}^{n-1} & \mu_{2}^{n-1} \cdot \mu_{n}^{n-1}
\end{array}\right]
$$

Using this notation we begin by letting $Y$ be a fundamental matrix for equation (3.1). Since $h$ is strictly increasing on $[a, \infty)$ we may let $g$ be the function inverse to it $(h(g(s))=s$ for $s \geqq 0)$ and let $Z(s)=Q(g(s)) Y(g(s))$ for $s \geqq 0$. Noting that $g^{\prime}(s)=1 / h^{\prime}(g(s))$ and 
that $Q(g(s))$ is nonsingular we see that $Z$ is a fundamental matrix for

$$
\begin{gathered}
z^{\prime}(s)=\left[1 / h^{\prime}(g(s))\right] \\
{\left[Q\left(g(s) M(g(s)) Q^{-1}(g(s))+Q^{\prime}(g(s)) Q^{-1}(g(s))\right] z(s)\right.}
\end{gathered}
$$

where $M$ is the coefficient matrix on the right hand side of equation (3.1). Computation shows that equation (3.2) is the same as

$$
z^{\prime}(s)=[A+\alpha(s) D+R(s)] z(s), s \geqq 0
$$

where

$$
\begin{gathered}
A=\left[\begin{array}{cccccc}
0 & 1 & 0 & \cdots & 0 & 0 \\
0 & 0 & 1 & \cdots & 0 & 0 \\
\cdot & \cdot & \cdot & \cdots & \cdot & \cdot \\
0 & 0 & 0 & \cdots & 0 & 1 \\
\lambda & 0 & 0 & \cdots & 0 & 0
\end{array}\right](n \times n), \\
\alpha(s)=\left[w^{\prime} / w^{1 / 1 n}\right](g(s)), \\
D=\operatorname{diag}\left[\alpha_{1}, \cdots, \alpha_{n}\right],
\end{gathered}
$$

and $R(s)$ is the $n \times n$ matrix having

$$
\left[\left(-p_{j} / w^{(j-1) / n}\right)\left(1 / w^{1 / n}\right)\right](g(s))
$$

as its $n, n-j+1$ entry for $2 \leqq j \leqq n$ and zero for all other entries. Since $h(t) \rightarrow \infty$ as $t \rightarrow \infty$ and

$$
\int_{0}^{h(b)}\left|\left[\left(p_{j} / w^{(j-1) / n}\right)\left(1 / w^{1 / n}\right)\right](g(s))\right| d s=\int_{a}^{b}\left|\left[\left(p_{j} / w^{(j-1) / n}\right)\right](t)\right| d t
$$

we see from condition (3) of the definition of $\ell$-admissible weight that $|R| \in \mathscr{L}(0, \infty)$ since by condition (2) of the definition it is the case that $\left[w^{\prime} / w^{1+1 / n}\right]^{\prime}$ and $\left.\left[w^{\prime} / w\right)^{2}\left(1 / w^{1 / n}\right)\right]$ are in $\mathscr{L}(a, \infty)$ we see from similar "changes of variable" that $\alpha^{\prime}$ and $\alpha^{2}$ are in $\mathscr{L}(0, \infty)$. Since $\alpha^{\prime} \in \mathscr{L}(\alpha, \infty)$ and $\alpha^{\prime}$ is continuous, $\alpha$ has a limit at $\infty$ and since $\alpha^{2} \in \mathscr{L}(0, \infty)$ this limit must be zero. The characteristic roots of $A$ are $\mu_{1}, \cdots, \mu_{n}$. Hence for $j=1, \cdots, n$ we may let $\lambda_{j}$ be the continuous function such that $\lambda_{j}(s) \rightarrow \mu_{j}$ as $s \rightarrow \infty$ and $\lambda_{j}(s)$ is a characteristic root of $A+\alpha(s) D$ for $s \geqq 0$.

We now shall show that $\lambda_{j}-\mu_{j} \in \mathscr{L}(0, \infty)$ for each $j$. Following the procedure used in [9] we note that

$$
\begin{aligned}
0 & =\operatorname{det}\left[A+\alpha(s) D-\lambda_{j}(s) I\right] \\
& =(-1)^{n+1} \lambda+\pi_{i=1}^{n}\left(\alpha_{i} \alpha(s)-\lambda_{j}(s)\right) \\
& =(-1)^{n+1} \lambda+\left(-\lambda_{j}(s)\right)^{n}+\left(-\lambda_{j}(s)\right)^{n-1} \alpha(s) \sum_{i=1}^{n} \alpha_{i}+\alpha^{2}(s) F(s),
\end{aligned}
$$


where $F$ is a bounded function. (Racall that $\alpha(s) \rightarrow 0$ and $\lambda_{j}(s) \rightarrow \mu_{j}$ as $s \rightarrow \infty$.) Noting that $\sum_{i=1}^{n} \alpha_{i}=0$ we then have

$$
0=(-1)^{n+1} \lambda+\left(-\lambda_{j}(s)\right)^{n}+\alpha^{2}(s) F(s)
$$

and

$$
0=(-1)^{n+1} \lambda+\left(-\mu_{j}\right)^{n}
$$

From which we conclude that

$$
\left(\lambda_{j}(s)\right)^{n}-\mu_{j}^{n}=-(-1)^{n} \alpha^{2}(s) F(s)
$$

and

$$
\left|\lambda_{j}(s)-\mu_{i}\right|\left|\sum_{i=1}^{n}\left(\lambda_{j}(s)\right)^{n-i} \mu_{j}^{i-1}\right| \leqq\left|\alpha^{2}(s) F(s)\right| .
$$

Since $\lambda_{j}(s) \rightarrow \mu_{j} \neq 0$ as $s \rightarrow \infty$, since $\alpha^{2} \in \mathscr{L}(\alpha, \infty)$ and since $F$ is bounded we see that $\left|\lambda_{j}(s)-\mu_{j}\right|$ is for all large $s$ dominated by a function in $\mathscr{L}(0, \infty)$; hence $\lambda_{j}-\mu_{j} \in \mathscr{L}(0, \infty)$.

Thus all the hypotheses of Thorem 8.1 p. 92 of [2] are satisfied and noting that the $j$ th column of $L$ is an eigenvector of $A$ corresponding to $\mu_{j}$ we are able to conclude that there exist numbers $s_{1}, \cdots, s_{n}$ and a fundamental matrix $Z_{0}$ for equation (3.3) such that

$$
Z_{0}(s) G(s) \longrightarrow L \text { as } s \longrightarrow \infty
$$

where

$$
G(s)=\exp \left\{\operatorname{diag}\left[-\int_{s_{1}}^{s} \lambda_{1}, \cdots,-\int_{s_{n}}^{s} \lambda_{n}\right]\right\} .
$$

Since $\lambda_{j}-\mu_{j} \in \mathscr{L}(a, \infty)$ it follows that there is a nonsingular diagonal constant matrix $H$ such that

$$
Z_{0}(s) H \operatorname{diag}\left[e^{-\mu_{1} s}, \cdots, e^{-\mu_{n} s}\right] \longrightarrow L \text { as } s \longrightarrow \infty .
$$

(See the procedure followed at the end of the proof of Theorem 2.3 in [12].) Since each of $Z_{0} H$ and $Z$ is a fundamental matrix for equation (3.3) there is a constant nonsingular matrix $C$ such that $Z_{0} H=Z C$. Letting $Y_{0}$ be $Y C$ and recalling that $Z(s)=Q(g(s)) Y(g(s))$ we have

$$
Q(g(s)) Y_{0}(g(s)) \operatorname{diag}\left[e^{-\mu_{1} s}, \cdots, e^{-\mu_{n} s}\right] \longrightarrow L \text { as } s \longrightarrow \infty .
$$

Hence $Q(t) Y_{0}(t) E(t) \rightarrow L$ as $t \rightarrow \infty$ and the theorem is proved.

4. Application. If $w$ is a weight on $[a, \infty)$ we denote by $\mathscr{L}^{2}$ $(w: a, \infty)$ the Hilbert space of all complex valued measurable $y$ such that

$$
\int_{a}^{\infty}|y|^{2} w<\infty
$$


with the obvious inner product. If $\ell$ is an $n$th formally self-adjoint (in the sense defined in [2]; see in particular 13 and 14 p. 204) operator, $w$ is a weight,

$$
\begin{aligned}
\mathscr{D}= & \left\{y \mid y \in \mathscr{L}^{2}(w: a, \infty), y^{(n-1)}\right. \text { is absolutely continuous } \\
& \text { and } \left.(1 / w) \measuredangle(y) \in \mathscr{L}^{2}(w: a, \infty)\right\}, \\
\mathscr{D}_{0}^{\prime}= & \{y \mid y \in \mathscr{D} \text { and has compact support interior to }[a, \infty)\} .
\end{aligned}
$$

and $L$ and $L_{0}^{\prime}$ are the restriction of $(1 / w)<$ to $\mathscr{D}$ and $\mathscr{D}_{0}^{\prime}$ respectively then $L_{0}^{\prime}$ is a densely defined symmetric operator in $\mathscr{L}^{2}(w: a, \infty)$, hence admits a closure $L_{0}$ in this space, and $L_{0}^{*}=L$ where $*$ denotes adjoint operator in $\mathscr{L}^{2}(w: a, \infty)$. Verification of these assertions closely parallels that for the case $w \equiv 1$ found in [1], [4], and [11].

The deficiency indices of $L_{0}$ are $\left(n_{1}, n_{2}\right)$ where $n_{j}$ is the dimension of the subspace of solutions to

$$
\ell(y)=(-1)^{j+1} \mathbf{i} w y
$$

which lie in $\mathscr{L}^{2}(w: a, \infty)$. (Actually for $\measuredangle$ formally self-adjoint any $\lambda$ in the upper half plane may be used for $\mathbf{i}$ and any $\lambda$ in the lower half plane for - i. See [4 Theorem 19, p. 1232, 5, and 6].)

By use of Theorem 2 we may conclude the following.

THEOREM 3. Let $\iota$ be as in 1.1 and let $w$ be an $\measuredangle$-admissible weight.

(1) If $n$ is even and $\operatorname{Im} \lambda \neq 0$ the dimension of the subspace of solution to equation 1.2 which lie in $\mathscr{L}^{2}(w: a, \infty)$ is $n / 2$.

(2) If $n=4 k+1=2 m+1$ and $\operatorname{Re} \lambda>0$ or if $n=4 k+3=$ $2 m+1$, and $\operatorname{Re} \lambda<0$ the dimension of the subspace is $m$.

(3) If $n=4 k+1=2 m+1$, and $\operatorname{Re} \lambda<0$ or if $n=4 k+3=$ $2 m+1$, and $\operatorname{Re} \lambda>0$ the dimension is $m+1$.

Proof. We begin by noting that for $c$ real, $w$ an $\ell$-admissible weight for some $\ell$, and $E \subset[a, \infty)$ with $E$ of infinite Lebesgue measure (for the first application below we will take $E=[a, \infty)$ ),

$$
\int_{E} \exp \left\{\int_{a}^{t} w^{1 / n}\left[c+(1 / n)\left(w^{\prime} / w^{1+1 / n}\right)\right]\right\} d t,
$$

is finite if $c<0$ and infinite if $c>0$. To see this recall that in the proof of Theorem 2 we showed that $\alpha(s)=\left[w^{\prime} / w^{1+1 / n}\right](g(s)) \rightarrow 0$ as $s \rightarrow \infty$. Hence $\left[w^{\prime} / w^{1+1 / n}\right](t)=\alpha(h(t)) \rightarrow 0$ as $t \rightarrow \infty$. Since $w(t) \rightarrow \infty$ as $t \rightarrow \infty$ we then see that $w^{1 / n}(t)\left[c+(1 / n)\left(w^{\prime} / w^{1+1 / n}\right)(t)\right]>c$ for $c>0$ and $<c$ for $c<0$ for all large $t$ and the above assertion is immediate. We next observe from Theorem 2 that if $w$ is an $\ell$-admissible 
weight then equation 1.2 has $n$ lineary independent solutions $U_{1}, \cdots, U_{n}$ (with $U_{j}=(w(\alpha))^{(n-1) / 2 n} y_{j}$ ) such that

$$
\left|U_{j}(t)\right|^{2} w(t)=(1+o(1)) \exp \left\{\int_{a}^{t} w^{1 / n}\left[2 \operatorname{Re} \mu_{j}+(1 / n)\left(w^{\prime} / w^{1+1 / n}\right)\right]\right\} .
$$

If $n=2 m$ and $\operatorname{Im} \lambda \neq 0$ we may arrange the $n$th roots of $\lambda$ so that

$$
\operatorname{Re} \mu_{1}<\operatorname{Re} \mu_{2}<\cdots<\operatorname{Re} \mu_{m}<0<\operatorname{Re} \mu_{m-1}<\cdots<\operatorname{Re} \mu_{n} .
$$

Thus each of $U_{1}, \cdots, U_{m}$ will lie in $\mathscr{L}^{2}(w: a, \infty)$; and if $c_{m+1}, c_{m+2}$, $\cdots, c_{n}$ are not all zero and $j$ is the largest integer with $m+1 \leqq j \leqq n$ such that $c_{j} \neq 0$ then

$$
\sum_{k=1}^{m} c_{m+k} U_{m+k}=c_{j} U_{j}(1+o(1)) \notin \mathscr{L}^{2}(w: a, \infty) .
$$

Hence the first assertion of the theorem is established.

In case $\operatorname{Im} \lambda \neq 0$ the last two assertions follow analogously upon noting that in Case 2 if $\operatorname{Im} \lambda \neq 0$ the $n$-th roots may be arranged so that

$$
\operatorname{Re} \mu_{1}<\cdots<\operatorname{Re} \mu_{m}<0<\operatorname{Re} \mu_{m+1}<\cdots<\operatorname{Re} \mu_{n},
$$

and that in Case 3 they may be arranged so that

$$
\operatorname{Re} \mu_{1}<\cdots<\operatorname{Re} \mu_{m+1}<0<\operatorname{Re} \mu_{m+2}<\cdots<\operatorname{Re} \mu_{m} .
$$

If $\lambda$ is real and positive and $n=4 k+1$ the roots may be arranged so that

$$
\begin{aligned}
\operatorname{Re} \mu_{1} & =\operatorname{Re} \mu_{2}<\operatorname{Re} \mu_{3} \\
& =\operatorname{Re} \mu_{4}<\cdots<\operatorname{Re} \mu_{2 k-1} \\
& =\operatorname{Re} \mu_{2 k}<0<\operatorname{Re} \mu_{2 k+1} \\
& =\operatorname{Re} \mu_{2 h+2}<\cdots<\operatorname{Re} \mu_{n-2} \\
& =\operatorname{Re} \mu_{n-1}<\operatorname{Re} \mu_{n},
\end{aligned}
$$

and so that if $\mu_{j}=\mu_{j+1}$ then $\operatorname{Im} \mu_{j+1}>0$. Then each of $U_{1}, \cdots, U_{2 k}$ is in $\mathscr{L}(a, \infty)$, and each of $U_{2 k+1}, \cdots, U_{n}$ is not in $\mathscr{L}^{2}(\alpha, \infty)$. It remains to be shown that no nontrivial linear combination of $U_{2 k+1}$, $\cdots, U_{n}$ lies in $\mathscr{L}^{2}(a, \infty)$ and to do this it is sufficient to show if $2 k+1 \leqq j<n$ with $j$ odd then no nontrivial linear combination of $U_{j}$ and $U_{j+1}$ lies in $\mathscr{L}^{2}(a, \infty)$.

Suppose that $c_{1} U_{j}+c_{2} U_{j+1} \in \mathscr{L}^{2}(w: a, \infty)$ with $c_{1}$ and $c_{2}$ not both zero and $j$ odd with $2 k+1 \leqq j<n$. Since $U_{j} \notin \mathscr{L}^{2}(w: a, \infty)$, it follows that $c_{1} \neq 0$ and $U_{j}+c U_{j+1} \in \mathscr{L}^{2}(w: a, \infty)$ where $c=c_{2} / c_{1}$. From Theorem 2 and the definition of $U_{1}, \cdots, U_{n}$ we have that 
$U_{j}(t)+c U_{j+1}(t)=U_{j}(t)\left[1+c\left(U_{j+1}(t) / U_{j}(t)\right)\right]$ is

$$
(1+o(1)) U_{j}(t)\left\{1+(c+o(1)) \exp \left[\int_{d}^{t} 2 \mathbf{i}\left(\operatorname{Im} \mu_{j+1}\right) w^{1 / n}\right]\right\} .
$$

For all large $t$. Hence $|c|=1$ for if $|c| \neq 1$ the term in \{\} would be bounded away from zero for all large $t$ and this would contradict the fact that $U_{j} \notin \mathscr{L}^{2}(w: a, \infty)$. Letting $E=\{t \mid$ modulus of term in 4.3 in \{\} is $\geqq \sqrt{2}\}$ we see since $w$ is increasing that $E$ is of infinite measure. (Think of the exponential term in 4.3 or giving the position of a particle on the unit circle at time $t$ moving counterclockwise at an ever increasing rate.) Hence from 4.3 we see that for some constant $K$,

$$
\int_{E}\left|U_{j}\right|^{2} w \leqq K \int_{a}^{\infty}\left|U_{j}+c U_{j+1}\right|^{2} w<\infty .
$$

But from 4.1 and 4.2 we see that

$$
\int_{E}\left|U_{j}\right|^{2} w=\infty
$$

must be the case. This contradiction shows then that $c_{1} U_{j}+c_{2} U_{j+1} \notin$ $\mathscr{L}^{2}(w: a, \infty)$.

The proofs of the remaining assertions when $\lambda$ is real are naalogous.

\section{REFERENCES}

1. N. I. Akhiezer and I. M. Glazman, Theory of linear operators in Hilbert space, Volume II, Frederick Ungar, New York, 1963.

2. E. A. Coddington and N. Levinson, Theory of ordinary differential equations, McGraw-Hill, New York, 1955.

3. A. Devinatz, The asymptotic nature of the solutions of certain linear systems of differential equations, Pacific J. of Math., 15 (1965), 75-83.

4. N. Dunford and J. T. Schwartz, Linear operators Part II, Interscience-Wiley, New York and London, 1963.

5. W. N. Everitt, Integrable-square solutions of ordinary differential equations, Quart J. Math., Oxford Ser (2), 10 (1959), 145-155.

6. - Integrable-square Solutions of ordinary differential equations, (II) Quart. J. Math., Oxford Ser (2), 13 (1962), 217-220.

7. M. V. Fedorjuk, Asymptotic methods in the theory of one-dimensional singular differential operators, Trans. Moscow Math. Soc., 15 (1966), 333-386 in Amer. Math. Soc. English Translation.

8. - Asymptotic properties of the solutions of ordinary $n^{\text {th }}$ order linear differential equations, Differential Equations 2 (1966), 250-258.

9. D. B. Hinton, Asymptotic behavior of the solutions of $\left(r y^{(m)}\right)^{(k)} \pm q y=0$. J. Differential Equations, 4 (1968), 590-596.

10. N. Levinson, The asymptotic nature of the solutions of linear systems of differential equations, Duke Math. J., 15 (1948), 111-126. 
11. M. A. Naimark, Linear Differential Operators Part II, Frederick Ungar, New York, 1968.

12. P. W. Walker, Asymptotics of the solutions to $\left[\left(r y^{\prime \prime}\right)-p y^{\prime}\right]^{\prime}+q y=\sigma y$, J. Differential Equations, 9 (1971), 1-25.

13. - Weighted singular differential operators in the limit-circle case, J. London Math. Soc., to appear.

Received January 19, 1971.

ViRginia POLYTEChNiC Institute

AND

StATE UNIVERSITY

BLACKSBURG, VIRGINIA 24061 


\title{
PACIFIC JOURNAL OF MATHEMATICS
}

\section{EDITORS}

\author{
H. SAMELSON \\ Stanford University \\ Stanford, California 94305 \\ C. R. HobBY \\ University of Washington \\ Seattle, Washington 98105
}

J. DugundJI

Department of Mathematics

University of Southern California

Los Angeles, California 90007

RICHARD ARENS

University of California

Los Angeles, California 90024

\section{ASSOCIATE EDITORS}
E. F. BECKENBACH
B. H. NeumanN
F. WOLF
K. YOSHIDA

\section{SUPPORTING INSTITUTIONS}

\author{
UNIVERSITY OF BRITISH COLUMBIA \\ CALIFORNIA INSTITUTE OF TECHNOLOGY \\ UNIVERSITY OF CALIFORNIA \\ MONTANA STATE UNIVERSITY \\ UNIVERSITY OF NEVADA \\ NEW MEXICO STATE UNIVERSITY \\ OREGON STATE UNIVERSITY \\ UNIVERSITY OF OREGON \\ OSAKA UNIVERSITY
}

\author{
UNIVERSITY OF SOUTHERN CALIFORNIA \\ STANFORD UNIVERSITY \\ UNIVERSITY OF TOKYO \\ UNIVERSITY OF UTAH \\ WASHINGTON STATE UNIVERSITY \\ UNIVERSITY OF WASHINGTON
AMERICAN MATHEMATICAL SOCIETY
NAVAL WEAPONS CENTER

The Supporting Institutions listed above contribute to the cost of publication of this Journal, but they are not owners or publishers and have no responsibility for its content or policies.

Mathematical papers intended for publication in the Pacific Journal of Mathematics should be in typed form or offset-reproduced, (not dittoed), double spaced with large margins. Underline Greek letters in red, German in green, and script in blue. The first paragraph or two must be capable of being used separately as a synopsis of the entire paper. The editorial "we" must not be used in the synopsis, and items of the bibliography should not be cited there unless absolutely necessary, in which case they must be identified by author and Journal, rather than by item number. Manuscripts, in duplicate if possible, may be sent to any one of the four editors. Please classify according to the scheme of Math. Rev. Index to Vol. 39. All other communications to the editors should be addressed to the managing editor, Richard Arens, University of California, Los Angeles, California, 90024.

50 reprints are provided free for each article; additional copies may be obtained at cost in multiples of 50 .

The Pacific Journal of Mathematics is published monthly. Effective with Volume 16 the price per volume (3 numbers) is $\$ 8.00$; single issues, $\$ 3.00$. Special price for current issues to individual faculty members of supporting institutions and to individual members of the American Mathematical Society: $\$ 4.00$ per volume; single issues $\$ 1.50$. Back numbers are available.

Subscriptions, orders for back numbers, and changes of address should be sent to Pacific Journal of Mathematics, 103 Highland Boulevard, Berkeley, California, 94708.

\section{PUBLISHED BY PACIFIC JOURNAL OF MATHEMATICS, A NON-PROFIT CORPORATION}

Printed at Kokusai Bunken Insatsusha (International Academic Printing Co., Ltd.), 270, 3chome Totsuka-cho, Shinjuku-ku, Tokyo 160, Japan. 


\section{Pacific Journal of Mathematics}

\section{Vol. 40, No. $2 \quad$ October, 1972}

Louis I. Alpert and L. V. Toralballa, An elementary definition of surface area in $E^{n+1}$ for smooth surfaces...........................

Eamon Boyd Barrett, A three point condition for surfaces of constant mean curvature........................................

Jan-Erik Björk, On the spectral radius formula in Banach algebras ....... 279

Peter Botta, Matrix inequalities and kernels of linear transformations . . . . 285

Bennett Eisenberg, Baxter's theorem and Varberg's conjecture ........... 291

Heinrich W. Guggenheimer, Approximation of curves .............. 301

A. Hedayat, An algebraic property of the totally symmetric loops associated with Kirkman-Steiner triple systems ....................... 305

Richard Howard Herman and Michael Charles Reed, Covariant representations of infinite tensor product algebras ................

Domingo Antonio Herrero, Analytic continuation of inner

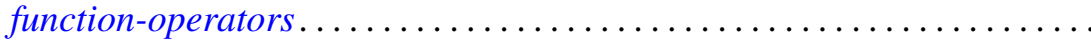

Franklin Lowenthal, Uniform finite generation of the affine group......... 341

Stephen H. McCleary, 0-primitive ordered permutation groups .......... 349

Malcolm Jay Sherman, Disjoint maximal invariant subspaces .......... 373

Mitsuru Nakai, Radon-Nikodým densities and Jacobians .............. 375

Mitsuru Nakai, Royden algebras and quasi-isometries of Riemannian manifolds. . .

Russell Daniel Rupp, Jr., A new type of variational theory sufficiency

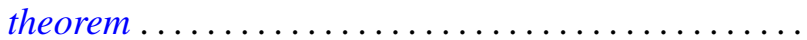

Helga Schirmer, Fixed point and coincidence sets of biconnected multifunctions on trees..........................

Murray Silver, On extremal figures admissible relative to rectangular

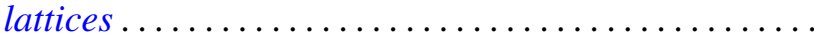

James DeWitt Stein, The open mapping theorem for spaces with unique segments ...

Arne Stray, Approximation and interpolation

Donald Curtis Taylor, A general Phillips theorem for $C^{*}$-algebras and some applications

Florian Vasilescu, On the operator $M(Y)=T Y S^{-1}$ in locally convex algebras...

Philip William Walker, Asymptotics for a class of weighted eigenvalue problems...

Kenneth S. Williams, Exponential sums over $\mathrm{GF}\left(2^{n}\right)$. 